\title{
Helen Salisbury: Is transactional care enough?
}

\author{
Helen Salisbury GP \\ Oxford
}

I'm lucky enough to have been in the same practice since 2002, and I'm still discovering things about the patients I look after, making connections that deepen my understanding of who they are and how illness affects them. Terms that have been used to describe me, or the kind of general practice that I think all patients should have, include old fashioned, nostalgic, or hopelessly unrealistic.

A distinction has been drawn between transactional and relationship based (or relational) care. In transactional care the patient has a specific need, a condition is diagnosed and treated, a risk factor is controlled, or a referral made. ${ }^{1}$ The quality of the medicine is judged by the efficiency of the transaction: we're "good" doctors if we can tick the boxes in the Quality and Outcomes Framework, follow guidelines, and keep within our prescribing budgets.

Relationship based care focuses on the interaction between patient and doctor. Although the medical activity may be similar, there's another dimension to consider, which is the quality of that interaction. Relationships and trust develop over time, and we know that continuity of care brings a reduction in medical activity-fewer investigations performed, fewer medicines prescribed and referrals made-and longevity increases. ${ }^{2}$

Given the shortage of doctors in UK general practice, there have been suggestions that we should work out which patients need continuity and would benefit most from an ongoing relationship with a single doctor. ${ }^{3}$ In the case of complex patients with multimorbidity, this could be a familiar team including a nurse and a pharmacist. We could then prioritise these patients to receive continuity, while everyone else would be offered an efficient transaction with a suitable practitioner. ${ }^{4}$
I see two immediate problems with the proposed division of patients. The first is that we really don't know, before we've met the patients, which category they fall into. Neither age nor the number of diagnoses on a patient's problem list are reliable indicators of complexity, in my experience.

The second is what sort of service patients want. Some would no doubt prefer to see an unknown doctor remotely at a convenient time than wait to see their named GP. For many others, starting afresh with a new GP is daunting, and they prefer to wait weeks to see one they know. In reality I suspect that most people don't want a choice between access and continuity - they want both: a timely appointment with a doctor they know and trust. If we're to avoid a future where the one-off, transactional encounter is the default, with continuity reserved for the lucky few, we need more GPs in stable practices. To achieve this, we need more resources and better support for primary care to make it the attractive specialty it was when I joined.

Competing interests: See www.bmj.com/about-bmj/freelance-contributors. Provenance and peer review: Commissioned; not externally peer reviewed.

1 lles V, Sweeney K, Vaughan Smith J. What makes good doctors practise bad medicine? 2009. http://www.reallylearning.com/Current_Projects/Learning_Sets/What_makes_good_ Doctors_practise_bad_medicine2_3_09.pdf.

2 Pereira Gray DJ, Sidaway-Lee K, White E, Thorne A, Evans PH. Continuity of care with doctors-a matter of life and death? A systematic review of continuity of care and mortality. BMJ Open 2018:8:e021161. 10.1136/bmjopen-2017-021161. 29959146

3 Palmer W. Is the number of GPs falling across the UK? Nuffield Trust blog. 8 May 2019. https://www.nuffieldtrust.org.uk/news-item/is-the-number-of-gps-falling-across-the-uk.

4 Rosen R. Divided we fall: getting the best out of general practice. Nuffield Trust research report. $5 \mathrm{Feb}$ 2018. https://www.nuffieldtrust.org.uk/research/divided-we-fall-getting-thebest-out-of-general-practice.

Published by the BMJ Publishing Group Limited. For permission to use (where not already granted under a licence) please go to http://group.bmj.com/group/rights-licensing/ permissions 